\title{
Los demonios de Heidegger
}

\author{
Cecilio de Oriol
}

Los demonios de Heidegger

Ángel Xolocotzi y Luis Tamayo

Prólogo de Franco Volpi

Editorial Trotta. Madrid, 1012

$\mathrm{M}$ artin Heidegger murió el 26 de Mayo de 1976. En esas fechas los trabajos sobre su obra ya sumaban una cantidad sustancial y lo configuraban como un pensador insustituible en la historia de la filosofía. Sin embargo (y salvo las noticias periodísticas inevitables) su biografía no era (aún) objeto de demasiadas indagaciones directas.

En 1983 Heinrich Wiegand Petzet publica "Auf einen Stern zugehen. Begegnungen mit Martin Heidegger, 1929-1976" un libro próximo y amistoso que presenta un Heidegger humano y familiar a la par que un pensador inigualable. Es un libro que se estima poco entre los que han optado por la "biografía dura" en su aproximación al filósofo, a pesar de que, aun siendo la visión de alguien que deja claro su afecto a la persona, ofreció por primera vez datos relevantes y reveladores sobre la vida y la personalidad de Heidegger.

En 1987 aparece el libro de Víctor Farías, "Heidegger et le nazisme", en el que el autor chileno, con su habitual forma polémica y su tendencia a ir directamente a las cosas, pone en la diana no solo el episodio del rectorado de Friburgo (y especialmente el discurso de toma de posesión) sino la pertenencia al partido y la coherencia de la filosofía heideggeriana con el programa del NSDAP. La capacidad de Farías para suscitar controversia es bien conocida (no hay más que recordar las reacciones a sus trabajos sobre Allende y sobre el partido socialista chileno) y su libro abre la veda para que desde distintas posiciones de la izquierda teórica se lance un anatema sobre el pensamiento heideggeriano y sobre todo aquel que ose decirse seguidor del anatematizado (Lilla en 2001, Faye en 2005 y, entre nosotros, Quesada en 2008). Sobre el libro de Julio Quesada que, en realidad, no es una biografía sino una crítica a la ontología heideggeriana en tanto que "ontología nazi", Jacinto Chozas ha escrito una interesante recensión que puede encontrarse en: http://phylosophybooks:info/files/Heidegger_y_el_nazismo.htlm.

Podemos decir que si el libro de Petzet es la visión del amigo y el de Farías la visión del disector implacable, ambos de alguna manera pueden verse como ejemplos de un hecho incontrovertible: se había abierto la caja de Pandora de la vida y milagros de Heidegger. Aunque, como ya sabemos, la caja de Pandora no fuese una caja sino una jarra.

En 1992, Ernst Nolte, que ya había escandalizado con su idea de un "fascismo genérico" y que se esforzó por encontrar una base común (y por ello tácticamente antagónica) entre el nazismo alemán y el comunismo soviético, publica "Martin Heidegger: Politik und Geschichte im Leben und Denken". Es un libro de clara defensa de las posiciones heideggerianas en relación a su posible connivencia con el régimen nazi y una definida reivindicación de la obra del filosofo de Messkirch (Es curioso que, a pesar de ser una obra que ilustra bien todos los episodios de la vida de Heidegger, entre ellos la ayuda personal que Nolte le prestó cuando los ocupantes franceses le incautaron de su casa y, lo que era mucho peor, su biblioteca, el libro de Xocolotzi y Tamayo no lo mencione ni lo incluya en la bibliografía).

Pero fue en 1994 cuando Rudiger Safranski, que ya tenía en su haber una muy buena biografía de Nietszche y otro libro no menos interesante sobre Schopenhauer, publica "Ein 
Meister aus Deutschland. Martin Hidegger und seine Zeit". Su trabajo se ha convertido en una obra de referencia por mucho que sus detractores pretendan situarla en el campo de las defensas disimulatorias de la vida de Heigdegger. Cuando aparece ese libro (traducido tres años después al español) Ignacio Sotelo, a la sazón profesor de la Universidad Libre de Berlín, escribe una reseña amplia ("La presencia inquietante de Heidegger", en Saber Leer, n 93, Marzo de 1996) en la que dice "Pensamiento, biografia e historia se entrelazan de tal modo en Heidegger que la pregunta por su conexión en los últimos años ha desplazado incluso a los estudios, exclusivamente académicos, de su pensamiento". Pero concluye diciendo que "El libro de Safranski no contesta satisfactoriamente las cuestiones que surgen a este respecto (en relación con la vinculación al nazismo) pero al menos ayuda a plantearlas".

Parece claro que la polémica estaba abierta y no cerrada. Es evidente a la vista del extenso listado de obras que se han publicado y de obras que aún se anuncian (Ángel Xocolotzi menciona la próxima aparición de su "Crónica de Heidegger" y cita también el proyecto de una biografía que prepara Alfred Denker para 2016).

Nada de esto debería extrañarnos. La figura de Martín Heidegger es lo suficientemente grande como para despertar exégesis y diatribas. Nada que no deba suscitar un pensador que merezca tal nombre. Su contemporaneidad, además, hace de tales tareas un quehacer apetecible. Pero no es tan frecuente que la figura, admirada o denostada, lo sea en función de su vida "extra filosófica" o, si se quiere, extrínseca en cierta medida al pensamiento que defiende o propugna. Cuando esto sucede la bibliografía se ve matizada por la biografía. Y las actividades y el comportamiento público del autor llegan en ocasiones a hacer que la persona que hay tras el pensador anule a éste o lo distorsione eficazmente. No siempre se trata de una opinión unánime. Hay quien sostiene que vida y filosofía no son algo distinto y que el pensamiento de todo el mundo (incluidos los más excelsos) esta fuerte e irremisiblemente ligado a la raíz de sus sentimientos $\mathrm{y}$, sobre todo, de su conducta. Tamayo comienza su parte del libro que comentamos, con una cita de Proust que recuerda que "la vida es inseparable de la obra", aunque el mismo Proust se niegue ("Contra Saint Beuve") a admitir que esta inseparabilidad pueda ser reducida al chismorreo o al mero dato biográfico. En el lado opuesto a Saint Beuve (que no a Proust), el mismo Heidegger, decía a su hijo (no biológico, pero si absolutamente aceptado) Herman "La gente debe dedicarse a mi pensar, la vida privada no tiene nada que ver con lo público". Algo así como "Dejad de hurgar en lo que nos os importa". (Entrevista con Volpi).

Era conocido la intención del filósofo de que sus andanzas vitales quedaran separadas, neta y nítidamente, de su obra. En el libro de Petzet, citado como una fuente amistosa y cercana a Heidegger, éste ya le insistía su amigo: "Mi vida no es en absoluto interesante".

Pero es claro que en el tiempo que ha inventado el reality show y que practica con entusiasmo el viejo y acreditado ajuste de cuentas ideológico, una tal pretensión es ilusoria. Y Martin Heidegger debía ser perfectamente consciente en los últimos años de su vida que la posibilidad de ser tratado como Aristóteles ("vivió, trabajó, murió", repetía él mismo del griego) no era aceptada ni, probablemente, aceptable. (Solo un pensamiento tangencial: ¿Cuántos conocen la leyenda de Aristóteles y la hetaira Phyllis? ¿Alguien recuerda la "invención" del "equus eroticus", que inmortaliza, entre miles de representaciones medievales, Hans Baldung en un grabado fechado en 1513? El viejo filósofo siempre tuvo quien le hiciera una versión amable de su aventura: una especie de clase práctica para su díscolo y apasionado discípulo Alejandro).

Dejemos aquí el tema general de la relación entre el autor (como sujeto) y su obra (como producto). El dedicarse a indagar en cómo era quien pensó en lugar de qué fue lo que pensó, siempre tendrá fervientes partidarios y no seré yo quien les lleva la contraria. La eterna polémica sobre las relaciones, causales y casuales, entre el autor y su obra se pone, en muchas ocasiones, en la primera línea del motivo para escribir. Es este un tema tan repetido como mal resuelto. Probablemente porque sea irresoluble en términos de racionalidad y se diluya y confunda en 
términos de apasionamiento. Y aquí, como tendremos ocasión de ver, razón y pasión son los dos elementos básicos de la trama.

El libro que comento es, en realidad, dos libros y varios apéndices que no por ser breves son menos interesantes. En total un volumen corto (apenas 211 páginas de texto) que se completa con un glosario de personajes citados (faltan algunos y sobran, probablemente, otros) y una cuidada y útil bibliografía para quien desee iniciarse en las ediciones de y sobre Heidegger. Al estar escrito originariamente en español (los autores son dos muy estimables profesores mexicanos) se mencionan las traducciones a nuestro idioma, omitiendo, sin embargo, en la bibliografía secundaria algunas de las fuentes originales en alemán.

Los dos libros del libro están escritos respectivamente por el profesor Xolocotzi y por el profesor Tamayo. El primero dedica su atención a la historia más personal de Heidegger y especialmente su relación con su esposa y sus amantes, aunque no desdeña entrar en la biografía convencional y en la evolución del pensamiento heideggeriano; el segundo se centra en la relación del filósofo con el partido nazi. Pero en ambos se entremezclan otros temas que son más novedosos y que aún no habían sido explorados con suficiente profundidad en la vida del filósofo: entre ellos el papel de Elfride, la esposa, y de Víctor von Gebsattel, el psiquiatra que lo trata y lo ingresa en su clínica tras lo que los autores denominan púdicamente "desfallecimiento" (Tamayo) y "colapso" (Xocolotzi) y que le acontece tras la derrota del III Reich.

La relación de Heidegger con las mujeres está bien documentada. Lástima que Xolocotzi, en un lógico deseo de sublimar lo que es fácilmente sublimable, se empeñe en achacar a un daimon personal (con referencias a la posesión y a la manía en su versión griega) lo que no aparece ante los ojos del observador imparcial sino con el efecto de una libido desatada y de un deseo bullente de seducir y poseer más los cuerpos que las mentes (aunque la posesión de las mentes fuera, en casi todas las ocasiones, la vía regia para llegar a los cuerpos). Hablar del "implacable atosigamiento del Eros" no cabe duda que dignifica mucho la imagen de un señor mayor intentando, sin descanso, meterse en la cama con toda la que se le pusiera a tiro.

Aunque el autor no se resiste a explorar la lista de las amantes, la relación de Heidegger con las mujeres se describe con respeto y casi con pudor. Ya lo hemos mencionado. El autor emplea abundantemente el paradigma griego de lo erótico y lo maniaco para insertar en este presentable contexto lo que no es más que el reflejo de la apetencia sexual de un hombre que pensaba, sí, pero al que también le gustaba el sexo. Su pensar centra su extraordinaria búsqueda del ser y de la existencia, la aventura sexual manifiesta que el mundo del deseo (al que nunca le prestó la más mínima atención teórica) ocupaba el otro polo de su vida. Y ese deseo se manifestaba (Xocolotzi lo relata bien bajo suaves y aceptables palabras) intentando seducir a cualquier mujer atractiva que aparecía en su campo de visión. Y el campo de visión más inmediato lo constituían sus alumnas. No en vano Elfride, su esposa, cuya relación se mantuvo a pesar de los "accidentes" amorosos del uno y de la otra, era, cuando la conoció, una alumna.

$\mathrm{Y}$ un punto de especulación razonable. No parece adecuado hablar de amor en toda esta serie de enredos. Es imposible asegurar que Heidegger amaba a sus mujeres. Sin duda que esa es la palabra que usa (y abusa) cuando tiene que dar cuenta a su, generalmente enfadada, esposa de que ha aparecido alguien nuevo en su vida y en su cama. Pero la misma manera con la que le asegura a Elfride que cortará radicalmente con la fémina de turno (y lo hace) impide pensar en algo personal y amoroso, en el mínimo sentido que se le puede dar a este término. Se dirá (y se dice) que hubo excepciones: La más conocida Hannah Arendt. La correspondencia entre ambos (que se publicó en 1999) da mucho que pensar y merecería una exégesis más detallada. En ella hay reflexiones de altura, palabrería y autojustificación y también cruda utilización del otro. Pero no nos engañemos: todas las relaciones fueron cortadas y diluidas, sin ningún tipo de miramiento, cuando se volvieron molestas o cuando Elfride intervenía.

Hemos visto como Xocolotzi habla del Eros hedeggeriano como un daimón que lo acompaña y, en cierta medida, lo tortura. Es una forma bonita de decirlo. Pero no hay mucha sofisticación, en el caso si fuese cierta la anécdota, de la petición del filósofo de una fotografía desnuda a una de su conquistas. No hay aquí sujeto amoroso, hay clara y tajante cosificación sexual de las más elementales. 
Heidegger siempre mantuvo la coartada intelectual bien a la vista tanto cuando iniciaba la conquista como cuando quería dar por zanjada la aventura. Y en ese terreno se movía como un seductor tradicional, cuyos mecanismos habituales usaba, y en el cual solo destacaba el uso como arma estratégica de la inteligencia y el brillo del pensamiento, antes de el atractivo físico y la seducción convencional. Pero la meta en Heidegger es la de cualquier donjuán de provincias: llevarse a la cama a la pretendida.

Hay en todo ello un cierto contraste con la tendencia general de Heidegger a que Elfride estuviese al corriente de sus andanzas (al menos a partir del momento en que estas eran descubiertas) y que, en cierta medida, que las aceptase y las aprobase. Hay una tendencia a reunir a la esposa y a la(s) amante(s) en muchas ocasiones. Y tampoco se desdeñaba la presencia y la relación cordial con los maridos en algunos casos.

Eso hace que en la vida de Heidegger la persona más importante es sin duda alguna su esposa Elfride. Personaje que merecería una investigación más detallada. Quizá la publicación de su correspondencia (2005) nos de pistas sobre esta mujer que estuvo siempre junto al hombre que la engañó y al que engañó. Aunque probablemente entren dudas acerca de si es legítimo usar esta palabra convencional (engaño). Es poco adecuada para definir el contexto en el que se movieron los protagonistas de la historia.

La relación adultera de Elfride con su antiguo novio, que tuvo como resultado el nacimiento de Herman, el hijo segundo, fue aceptada "con estoica liberalidad" dice Xocolotzi, pero es significativo que sirva para que el filosofo le diga a su esposa "no querer un 'amor primitivo', sino una relación madura, libre y abierta". Palabras que, si se quiere, pueden sonar enigmáticas y complejas o, por el contrario, vulgares y elementales. En cualquier caso no cabe duda que Heidegger las puso en práctica (al menos por lo que a él le tocaba) con auténtica fruición.

Pero dejemos el tema de la sexualidad de Heidegger y de su tendencia a intentar que su esposa aceptara "llevarse bien" con una especie de harén de sucesivas alumnas inteligentes y atractivas. Parece que Heidegger quería tener a todas las mujeres que le gustaban, pero quería también mantener las relaciones con sus maridos y de todos ellos con Elfride. Es esta una conducta interesantísima que no es posible rastrear con total precisión pero que deja con ganas de profundizar en ella. Lo que sí parece claro es que hay algo más que una pura estrategia de supervivencia. Se puede olfatear una visión peculiar del sexo y de la amistad, que nunca explicitó pero que rezuma de toda esta historia.

Los otros temas son más conocidos a excepción quizá de la importancia que se le da al episodio del tratamiento por Gebsattel tras la penosa (y peligrosa) situación que se dio en la inmediata postguerra y que, no hay duda, atenuó el hecho de que las acciones de depuración antinazi se llevaran a cabo en el sector francés de ocupación. Al parecer no hay posibilidad alguna de recuperar los archivos clínicos en donde quedarían las huellas técnicas de tal tratamiento. La relación entre el filósofo y su psiquiatra queda solo en las menciones que los protagonistas hicieron. Y son escasas y escuetas. Heidegger mismo las minimizó cuando dijo que Gebsattel "solo lo acompañaba a dar paseos".

La segunda parte del libro (el "segundo libro") lo escribe, como ya decíamos, Luis Tamayo. Se centra en la vida política del filósofo y menciona, si bien introduciendo matices de racionalidad, todo lo que se ha dicho ya sobre el tema de sus relaciones con el NSAP, del acceso al rectorado y especialmente del discurso de investidura, de su comportamiento autoritario, de sus informes negativos sobre determinados profesores, de su afiliación al partido y del proceso de desnazificación que sufre, inevitablemente, tras la derrota de Alemania. A pesar de los esfuerzos para poner a Heidegger en una posición "obligada por los acontecimientos" no hay duda que el filósofo tuvo conductas de claroscuro con Husserl (aunque la historia de su ausencia en las exequias del maestro se haya justificado hasta la saciedad) con Jaspers (al que pide ayuda cuando está en el proceso de investigación de las autoridades francesas) y con otros muchos. La publicación de la extensa correspondencia que mantuvo con estos y otros personajes a lo largo de su vida lo pone claramente de manifiesto. 
Es evidente que esta segunda parte (o segundo libro) está dentro de lo que ya se conocía y se discutía. La posición de Tamayo es claramente justificativa y sus razones no son baladíes. Pero a excepción del episodio del ingreso en el hospital psiquiátrico, no hay demasiados datos nuevos.

El libro termina con tres esplendidos apéndices que unidos al prólogo de Franco Volpi acompañan estupendamente la lectura. En cierta medida se podría decir que el orden de lectura aconsejable es el prólogo seguido de las tres entrevistas finales para después, y solo después, pasar al cuerpo central de la obra.

Las entrevistas son dos de ellas con una figura tremendamente interesante: Herman Heidegger. La primera la realiza el mismo Xocolotzi, la segunda es un alimón con Volpi y Antonio Gnoli. La tercera es otra conversación de nuevo de Volpi con Hans Georg Gadamer, sobre el maestro.

Solo unas palabras sobre ellas. Herman se revela como el albacea intelectual de su padre por deseo explícito de éste y al tiempo habla con indisimulada amargura de cómo su madre entregó a Gertrud (la hija mayor del único hijo biológico de Heidegger, Jörg) toda la correspondencia entre Elfride y el filósofo. También queda claro el intento de Herman para conocer o intervenir siquiera, en la posible publicación de esas cartas y la total negativa de su sobrina a permitírselo. Es un episodio que parece tener más alcance que una simple discrepancia doméstica y señala una zona que aún está necesitada de aclaración (mas aún cuando sus protagonistas están, afortunadamente, aún vivos).

¿Qué nos queda de la persona de Heidegger tras este breve, intenso y jugoso libro? Pues la imagen de un hombre que quiso hacer del pensar el eje de su vida, que pensó y pensó bien; que al tiempo se comportó como una especie de rijoso personaje en el que el sexo y la pasión jugaron más de lo que podía parecer; que creyó, en algún momento al menos, que podía "domar", desde su superioridad intelectual, la carrera suicida de su país hacia el desastre; que no tuvo el más mínimo reparo en despreciar todo aquello que no le parecía que estaba a su altura pero que, al mismo tiempo, tampoco tuvo reparos en solicitar ayuda de aquellos a los que no había ayudado cuando se la pidieron a él.

Un retrato en el que la inteligencia, la egolatría, el deseo, el autoritarismo y la mezquindad hacen acto de presencia.

Quizá simplemente un ser humano. 